\title{
A REDE DE RELAÇÕES SOCIOECONÔMICAS DA VALE S.A.: UMA ANÁLISE DA ESTRATÉGIA CORPORATIVA E SEUS CONDICIONAMENTOS FINANCEIROS
}

\author{
Vale S.A's network of socioeconomic relations: an analysis of corporate \\ strategy and its financial conditionings
}

\author{
Maíra Sertã Mansur' \\ Rodrigo Salles Pereira dos Santos ${ }^{2}$
}

\begin{abstract}
Resumo
0 artigo discute a dependência por parte da corporação transnacional (CTN) extrativa Vale S.A. - antiga Companhia Vale do Rio Doce, que opera desde sua privatização, em 1997, como uma empresa de capital aberto - de recursos econômicos externos a ela, buscando mapear e descrever a diversidade de formas e condições da obtenção e acesso constante aos recursos financeiros em uma rede de relações economicamente relevantes para a conformação da organização e de sua estratégia financeira. Dessa forma, a referida rede de relações assume dimensão ontológica, ao reconfigurar o agente em questão e suas formas de ação concreta. Metodologicamente, mobilizamos a análise qualitativa de relatórios financeiros da empresa com o auxílio do software NVivo 10. Em última análise, os dados indicam um processo de "externalização" da estratégia de financiamento da CTN, e aponta-se para uma ampliação do papel dos investidores externos na corporação, em detrimento de agentes estatais e privados nacionais.
\end{abstract}

Palavras-chave: Sociologia econômica; Estratégia financeira; Rede de financiamento, Mineração; Vale.

\begin{abstract}
The paper aims at discussing the dependence of an extractive Transnational Corporation, Vale SA. former Companhia Vale do Rio Doce, which has been operating since its privatization in 1997 as a publicly held company - on external economic resources, by mapping and describing the diversity of forms and conditions for the company to obtain ongoing access to financial resources in a network of relations which are economically relevant for designing both the organization and its financial strategy. Accordingly, such a network of relationships has an ontological quality, being able to reshape the actor itself and its concrete forms of action. Methodologically, we mobilized a qualitative analysis of the company's financial reports with the assistance of NVivo 10 software. Ultimately, the data indicate a process of "externalization" of Vale's financial strategy and disclose an expansion of the role of foreign investors, to the detriment of government actors and national investors.
\end{abstract}

\footnotetext{
1 Doutoranda Universidade Federal do Rio de Janeiro (UFRJ), Instituto de Filosofia e Ciências Sociais (IFCS), Programa de Pós-Graduação em Sociologia e Antropologia (PPGSA), anadido@gmail.com Cidade: Rio de Janeiro.

2 Professor Doutor Universidade Federal do Rio de Janeiro (UFRJ), Instituto de Filosofia e Ciências Sociais (IFCS), Programa de Pós-Graduação em Sociologia e Antropologia (PPGSA), Departamento de Sociologia, santosrodrigosp@gmail.com Cidade: Rio de Janeiro.
} 
A rede de relações socioeconômicas da Vale S.A. | Maíra Sertã Mansur \& Rodrigo Salles P. dos Santos

Keywords: Economic sociology; Financial strategy; Financial network; Mining; Vale.

\section{Introdução}

O presente trabalho tematiza a dependência por parte de uma corporação transnacional (CTN) de recursos econômicos externos a ela, buscando identificar a diversidade e hierarquização das formas e condições da obtenção e acesso constante a esses recursos em uma rede de relações economicamente relevantes (WEBER, 1999) para a conformação da organização e de sua estratégia financeira. Dessa forma, a relevância econômica das relações em rede assume dimensão ontológica, ao reconfigurar o agente em questão e suas formas de ação concretas.

O objeto empírico em questão remete à Vale S.A. (Vale) e a um conjunto diversificado de agentes econômicos que atuam ao seu redor, tais como o Banco Nacional de Desenvolvimento Econômico e Social (BNDES), fundos de pensão e investidores institucionais, dentre outros. Dessa forma, a investigação questiona se as relações socioeconômicas estabelecidas pela Vale em termos de obtenção e acesso a recursos econômicos externos conformariam, assim, suas ações a partir das oportunidades e limites colocados por esses agentes, pelos mecanismos e instrumentos que mobilizam e, principalmente, pela rede de financiamento que conformam.

A hipótese levantada é a de que a composição da rede de financiamento da Vale vem se modificando rapidamente, com destaque para a emergência de investidores institucionais estrangeiros, em detrimento dos fundos de pensão, banco de desenvolvimento e do Estado brasileiro, o que produz impactos específicos na estrutura organizacional da corporação, que passa a emular o padrão setorial da mineração e normas e regras definidas no âmbito dos mercados de capitais. A análise apresentada, evidencia o inevitável enraizamento sociopolítico da empresa e as relações de poder postas.

Dessa maneira, tendo em vista a operação da corporação em indústria e mercado globais, o trabalho mobiliza um enquadramento teóricometodológico em rede, e apropriado à forma assumida pela organização da estratégia financeira da corporação. Correspondentemente, seu enquadramento teórico abarca contribuições do subcampo da sociologia econômica e, em particular, dos estudos sociais das finanças, assim como do 
debate interdisciplinar em torno dos sistemas transnacionais de produção e, especial, da abordagem das Redes Globais de Produção (RGPs) (HENDERSON et al., 2011; SANTOS, 2011).

Dessa forma, busca-se discutir as configurações específicas de influências e interdependências das CTNs frente a alguns agentes econômicos, que, no setor extrativo, se acentuam e diversificam a partir da emergência de um regime de competição baseado no imperativo da geração de valor aos acionistas - shareholder value, ou seja, de um modelo de negócios que prioriza o interesse dos acionistas frente aos outros stakeholders (FROUD et al., 2000, p. 103).

Isto posto, a definição de sucesso de uma corporação passa a depender da avaliação financeira de seus ativos econômicos, estando ancorado nas percepções dos agentes financeiros (fundos de pensão, acionistas individuais, etc.) e dos agentes de suporte ao mercado financeiro (agências de rating, jornalistas econômicos, etc.) sobre aqueles ativos. Isso significa que as formas e a continuidade do acesso a recursos econômicos externos à corporação dependem da capacidade da mesma de se representar como "sólida", "saudável”, "atraente” aos investidores (RÓSTAS, 2015).

A investigação empírica mobiliza predominantemente análise documental, debruçando-se sobre a análise de relatórios da corporação, com o objetivo de identificar e hierarquizar os agentes econômicos que compõem a rede de relações socioeconômicas da Vale. Dessa forma, a investigação enfocou a análise qualitativa dos relatórios Form 20-F (VALE, 2017a), do Formulário de Referência (VALE, 2017b) e do relatório Proposta para Destinação do Resultado financeiro da Vale (VALE, 2017d), lançados no ano de 2017 (referentes ao exercício de 2016).

Os relatórios foram lidos e codificados tematicamente com o auxílio do software NVivo 10, tendo permitido a formulação de hipóteses e identificação de indicadores que buscaram fundamentar a interpretação final. O processo de codificação indutiva permitiu a organização do material por meio da atribuição de categorias a trechos sucessivos de texto, estabelecendo níveis de relações diretas e indiretas entre a Vale e agentes econômicos externos. A análise documental realizada se apoiou, assim, na compilação de palavras com maior ocorrência (nivel informacional/quantitativo) e na confrontação 
entre texto e contexto (nivel social/hermenêutico) a partir da proposta da Análise Sociológica do Discurso (AQUINO, 2014).

Dessa forma, o artigo está dividido em três seções, além desta Introdução. Na seção 2, pretende-se apresentar as principais contribuições teóricas que fundamentaram a análise. Em seguida, é realizada uma descrição não exaustiva da Vale e de sua rede de financiamento, com foco em suas modificações recentes. Em sua primeira parte, são discutidas as fontes de financiamento, a estratégia financeira e a emergência de uma "nova governança corporativa" da Vale. A segunda parte da seção discute, por sua vez, a reconfiguração hierárquica da rede de financiamento, se detendo especificamente sobre o papel assumido pelos investidores institucionais estrangeiros. Finalmente, a seção conclusiva discute os principais resultados preliminares, fazendo um balanço da análise e apontando seus limites e desdobramentos futuros.

\section{A dinâmica em rede da financeirização}

Ao enfocar a dimensão financeira de uma CTN específica, investigando as formas variadas de obtenção de recursos externos, o mercado financeiro torna-se um componente indispensável. Observa-se um cenário de elevada dependência de recursos externos pelas CTNs, condicionando estratégias que facilitem seu acesso, e tornando o mercado financeiro determinante na configuração das mesmas. Assim, essa seção define o conceito de finanças e aborda especificamente discussões referentes à concepção de governança corporativa.

Dessa maneira, a contribuição dos estudos sociais das finanças é primordial à medida que se debruça sobre o mercado financeiro, seus mecanismos e processos de institucionalização e performatividade (CALLON, 1998; CALLON; MUNIESA, 2005; MACKENZIE; MUNIESA; SIU, 2007). Em paralelo, essa literatura enfoca as dinâmicas de conhecimento subjacentes às transações financeiras, evidenciando os processos sociais fundantes dos conceitos e modelos formais nos quais se assenta esse mundo social (PREDA, 2001).

Assumindo a corporação como o nó central de redes de relacionamento complexas, a estratégia corporativa é vista "como um 
repertório de ações coordenadas [...] que envolve o exercício do poder com o objetivo de: (1) aumentar sua capacidade de ampliar ou capturar valor; (2) ampliar seu poder ou reduzir o poder de outros agentes; ou (3) modificar condições de enraizamento" (MILANEZ et al., 2018, p. 6), em uma abordagem propriamente relacional. Assim, a execução da estratégia é condicionada, fundamentalmente, por agentes e redes de financiamento e só pode se efetivar por meio de adaptações às configurações econômicas, sociais, políticas, institucionais, culturais e etc. que conformam o mundo social das finanças (PREDA, 2001).

Como observa Van der Zwan (2014), o termo finanças tem sido utilizado para descrever a gestão do dinheiro e de outros ativos por famílias, empresas e governos, enquanto a noção de capitalismo financeiro denota o modo através do qual as finanças se tornaram a função dominante na economia e expandiram sua influência para outras áreas da vida. Assim, a financeirização refere-se à rede de processos inter-relacionados - econômicos, políticos, sociais, tecnológicos, culturais, etc. - através das quais as finanças ampliaram sua influência para além do mercado e para outros domínios da vida social (VAN DER ZWAN, 2014, p. 101).

Desta maneira, a financeirização descreve uma tendência recente, a partir do final do século XX, em que as finanças e considerações financeiras tornaram-se cada vez mais centrais para o funcionamento da economia. $\mathrm{O}$ conceito ganhou relevância principalmente porque marca uma descontinuidade fundamental entre a economia do pós-guerra, impulsionada pela produção industrial e comércio de bens, e a economia contemporânea, focada principalmente em indicadores financeiros (DAVIS; KIM, 2015).

Assim sendo, o processo de financeirização constitui propriamente uma variante contemporânea da mudança social, por meio da qual o financiamento como obtenção de recursos externos por agentes individuais e coletivos passa a ser intermediado por mercados especializados, em detrimento de organizações como bancos e instituições de suporte. Esse processo modifica significativamente as relações de poder e os modos pelos quais fluem os recursos econômicos, isto é, como o dinheiro é canalizado dos poupadores (investidores) para os mutuários (famílias, empresas, governos) e 
retorna acrescido aos primeiros, sob diferentes formas. Tal processo reconfigura as instituições sociais de forma fundamental (DAVIS; KIM, 2015).

Sob esse enquadramento, as finanças passam a desempenhar, a partir dos anos 1970, uma função especializada e preponderante frente a outras esferas econômicas (produção, consumo e distribuição ou troca): a de polo fornecedor e controlador do crédito (KNORR CETINA; PREDA, 2012). Assim, à medida que o crédito precisa ser obtido antes que um ciclo de produção possa se iniciar, essa especialização pode ser entendida como indutora de um efeito de autonomização (POLANYI, 2000) em relação às relações sociais. Importante evidenciar que ao mobilizar elementos de perspectivas distintas sobre o mercado considera-se que governos, legislações, poder e normas são conceitos essenciais na análise aqui apresentada. Entretanto, mesmo que esses sejam conceitos secundários na teoria performativa, a mesma enseja reflexões sobre a legitimidade da esfera econômica e das novas tecnologias que nos ajudam a refletir sobre a centralidade do mercado financeiro e seus dispositivos.

Neste contexto, estruturas sociais e econômicas são redefinidas de modo difuso pelo mundo social das finanças (PREDA, 2001) à medida que a orientação da geração de valor aos acionistas passa a predominar como principio orientador do comportamento corporativo. Em paralelo, na medida em que as práticas corporativas passam a convergir para a maximização do retorno de dividendos aos acionistas, os rentistas, ou seja, aqueles que vivem de renda proveniente da aplicação de capitais, emergem como grupo social amplo e dotado de interesses próprios.

Em particular, em âmbito corporativo, a financeirização passaria a desempenhar papel disciplinador. Nesse sentido, a cisão entre controle e propriedade das corporações tornar-se-ia normativa, com os quadros dirigentes passando a ser recompensados (e/ou punidos) de acordo com sua capacidade de aumentar o valor de mercado daquelas e, portanto, sendo conduzidos a alinhar seus interesses aos dos acionistas (DAVIS, 2012, p. 87). Desse modo, o disciplinamento dos quadros diretivos passa pelo ativismo dos acionistas e pela compensação baseada em desempenho, redefinindo a eficiência corporativa como a capacidade de maximizar os dividendos e manter elevados os preços das ações (FLIGSTEIN, 1996). Como consequência, se observou um crescente interesse em ações listadas em bolsas de valores, que 
fez surgir uma variedade ampla de serviços e produtos financeiros, tais como novos tipos de empréstimos, numerosos e diversificados fundos de investimentos e uma vasta gama de produtos derivativos (HEILBRON, 2005).

No plano da ação econômica e da micropolítica da firma (MORGAN; KRISTENSEN, 2006), o valor ao acionista tornou-se um modus operandi dominante, capaz de reorientar as modalidades específicas de governança corporativa (FROUD et al., 2000). Dessa forma, a financeirização reestruturou a hierarquia dos objetivos de gestão, pois reorientou a firma: se antes as empresas tinham que organizar processos e agradar consumidores em mercados de produtos, elas agora também devem satisfazer os gestores de fundos e atender às expectativas do mercado de capitais (WILLIAMS, 2000).

Deste modo, bolsas de valores e empresas listadas viram surgir, de forma inédita, agentes poderosos e formas de exercício de poder centradas nos acionistas (HEILBRON, 2005). Em vista disso, a forma de competição emergente representada pela financeirização envolve não apenas uma orientação estratégica para a obtenção de resultados financeiros, mas também uma espécie de compressão temporal da governança corporativa ou shorttermism (JACKSON; PETRAKI, 2011) e a aceleração no trabalho de gestão (FROUD et al., 2000, p. 104).

De forma ampla, a governança corporativa envolve relações entre múltiplos stakeholders, como acionistas individuais, investidores institucionais, bancos, funcionários, sindicatos e vários grupos de gerentes. A mesma também é vista como inserida em várias regras e crenças institucionais que moldam o modo como essas partes interessadas interagem na tomada de decisões corporativas - incluindo o direito corporativo, o sistema financeiro, o direito do trabalho, as relações de trabalho, os padrões de carreira prevalecentes e as ideologias de gestão (JACKSON; MIYAJIMA, 2007).

No Brasil, representantes da sociologia econômica e das finanças, como Grün (2015), Sartore (2010) e Leite (2011) também abordam os arranjos institucionais da ação, os agentes e as formas de propriedade e controle que conformam a governança corporativa, privilegiando, no entanto, o ponto de vista dos agentes externos e os parâmetros que eles podem manejar; em detrimento de uma visão endógena (GRÜN, 2015). 
A governança corporativa, pode ser entendida, assim, a partir das formas de disciplinamento financeiro que engendra, modelando o comportamento de proprietários e dirigentes nos âmbitos da corporação e do mercado (SANTOS, 2017). Em especial, nessa acepção, o foco recai sobre a difusão de instituições próprias ao regime anglo-americano - o financiamento via mercado de capitais, a dispersão da estrutura de propriedade, a força do mercado para controle corporativo e a flexibilidade do mercado de trabalho (AGUILERA; JACKSON, 2003, p. 447) - e sua pressão normativa sobre outros regimes de governança, nesse caso, o brasileiro.

Seguindo esta lógica, de acordo com Heilbron (2005), a tendência das empresas, desde os anos 1980, tem sido pagar dividendos mais altos, em vez de assegurar reserva de dinheiro para investimento, tornando a questão do acesso ao crédito elemento central da estratégia corporativa (SANTOS; MILANEZ, 2017). De acordo com Knorr Cetina e Preda (2005), o sistema financeiro controla e gerencia o crédito nas sociedades contemporâneas, criando forte dependência da figura do investidor para o fornecimento dos fundos com os quais as corporações adquirem os recursos de que necessitam. Desse modo, os mercados financeiros são, assim, um componente importante, senão o mais importante, do mecanismo de crédito nas economias baseadas no risco (KNORR CETINA; PREDA, 2005). Consequentemente, as finanças referem-se a transações e não simplesmente a fluxos de dinheiro (SASSEN, 2006, p. 19).

Nesses termos, as empresas são mais dependentes de conexões, grandemente internacionais, e de formas complexas de enraizamento de rede (HESS, 2004; HENDERSON et al., 2011) para o financiamento de suas atividades, o que tem implicações importantes para suas atividades operacionais. Sendo assim, a competição internacional dos resultados financeiros (FROUD et al., 2000) significa que é cada vez mais comum para as empresas listarem-se em múltiplos mercados de capitais de maneira a maximizar as fontes de obtenção de recursos. Entretanto, a multiplicação dos nós assim promovida encerra a necessidade de adaptação de suas operações às demandas dos mercados de capitais (HEILBRON, 2005, p. 10). 


\section{As mudanças na rede de financiamento da vale: A Estratégia Financeira e a "Nova Governança Corporativa"}

A presente seção apresenta a Vale e as transformações recentes em sua rede de financiamento, tendo em conta a demanda intensiva por capital do subsetor mineral de ferro. A corporação é a maior mineradora do Brasil, tendo seu valor sido estimado em R 252,95 bilhões em abril de 2018 (MAMONA, 2018). A Vale é um player mundial na produção e exportação de ferro, correspondendo a 70\% do mercado nacional deste minério (Vale, 2017f). É também a segunda maior produtora de níquel do mundo, destacando-se ainda na produção de manganês, cobre, carvão, pelotas, ferroligas e fertilizantes. Encontra-se presente em 26 países e atua a partir de uma rede que integra mineração, logística, energia e siderurgia (VALE, 2017f)

Nos últimos anos, as principais fontes de recursos da empresa têm sido o fluxo de caixa operacional e os empréstimos (VALE, 2017a; 2018). Apenas em 2017, o fluxo de caixa operacional da companhia atingiu o valor de US\$12,5 bilhões, enquanto o crédito privado disponivel chegou a US\$ 5,5 bilhões e os empréstimos públicos efetivos a US\$ 6,4 bilhões (VALE, 2018). Não obstante, mudanças recentes em sua estratégia corporativa, incluindo a adoção de novas regras de governança corporativa pela empresa (SANTOS, 2016; 2017), com ênfase em sua dimensão financeira, vêm apontando para a redução da importância do endividamento, em favor da alienação de ativos, que rendeu US\$ 1,2 bilhão à empresa em 2017 (VALE, 2018) e da atração de investidores.

O fluxo de caixa operacional da companhia é fortemente afetado pelos preços globais dos produtos comercializados, especialmente o minério de ferro. Em 2017, a empresa gerou fluxo de caixa de US\$ 12,45 bilhões. Por sua vez, sua divida líquida havia decrescido de US\$ 25 bilhões em 2016, atingindo o patamar de US\$22,49 bilhões em 2017.

Essa redefinição na estratégia financeira da Vale vem sendo acompanhada, não coincidentemente, por uma mudança nos arranjos de propriedade e controle da empresa (SANTOS, 2017). Assim, até 2017, sua constituição acionária era marcada pela existência de um grupo controlador, a holding company Valepar ${ }^{3}$. A estrutura da Valepar se caracterizava pela

3 Desde sua privatização, em 1997, a companhia operou através de um acordo de acionistas. Esse dispositivo sociotécnico, que vem regendo as relações entre os vários grupos de controle da empresa, 
presença: (i) dos três maiores fundos de pensão ${ }^{4}$ do país, PREVI, PETROS e FUNCEF, vinculados ao Banco do Brasil, Petrobrás e Caixa Econômica Federal, respectivamente; (ii) da BNDES Participações S.A. (BNDESPar), holding que administra as participações acionárias do BNDES; (iii) de investidores nacionais, dentre os quais, institucionais, de varejo, do Fundo Mútuo de Privatização e do Fundo de Garantia do Tempo de Serviço (FMPFGTS5); e (iv) do próprio Governo Federal, por meio de 12 ações de tipo golden share6 (VALE, 2016).

Entretanto, em um processo que abrangeu quase todo o ano de 2017, com sinalizações mútuas entre companhia e controladora, acionistas, gatekeepers $^{7}$, investidores estrangeiros, jornalistas econômicos e mercado de capitais, a Vale implementou sua "nova governança corporativa" (SANTOS, 2017), caracterizada pela reformulação de suas estruturas de propriedade e de governança.

Em primeiro lugar, a companhia foi bem-sucedida na unificação da estrutura acionária, tendo realizado em duas etapas a conversão de suas ações preferenciais em ordinárias, com substancial (84,4\%) adesão voluntária de seus acionistas entre junho e agosto de 2017 e substituição obrigatória até novembro do mesmo ano (VALE, 2018, p. 5).

Por sua vez, a Vale fez sucessivas alterações em seu Estatuto Social com vistas a adequar-se às regras mais rígidas do segmento de listagem Novo Mercado da B3, em especial, a restrição a ações preferenciais na estrutura acionária e a presença de número mínimo de membros independentes em conselhos de administração (BM\&FBOVESPA, 2017; SANTOS, 2017). Dessa

onde a Valepar é a holding e a Previ a sua maior acionista, foi substituído por um novo acordo em 2017 com vigência máxima prevista até 2019 , de modo que a corporação deve passar a operar sem qualquer tipo de acordo formal a partir de 2020 (Santos, 2017).

4 Agentes econômicos caracterizados por horizontes de investimento de longo prazo e alguns dos principais fornecedores desse tipo de capital. No caso em questão, PREVI, PETROS e FUNCEF atuam coletivamente, através da Litel participações S.A., possuindo destaque na composição acionária da empresa.

5 Utilizando recursos do Fundo de Garantia por Tempo de Serviço (FGTS), trabalhadores puderam adquirir as ações das empresas privatizadas no contexto do Plano Nacional de Desestatização (PND) ou dos Programas Estaduais de Desestatização, por meio de Fundos Mútuos de Privatização (FMP) criados por instituições financeiras (bancos, bancos de investimentos, corretoras ou distribuidoras de valores autorizadas).

6 No Brasil, o mecanismo foi introduzido pela lei $\mathrm{n}^{\circ} 8.031$, de 12 de abril de 1990. Da forma como foram criadas, as golden shares são ações de classe especial, detidas pelo Estado. O poder que conferem ao governo é definido no estatuto da empresa privatizada (Pela, 2008).

7 Gatekeepers são profissionais e instituições do mercado de valores mobiliários e sua atuação consiste na imposição de deveres de acompanhamento, fiscalização e de observância do ordenamento jurídico, a serem cumpridos pelos profissionais e instituições que prestam serviços a emissores e a investidores no mercado de valores mobiliários, sob pena de responsabilização (Haensel, 2014). 
A rede de relações socioeconômicas da Vale S.A. | Maíra Sertã Mansur \& Rodrigo Salles P. dos Santos

forma, agrupamentos de acionistas minoritários e controladores, preferencialistas e ordinaristas se defrontaram em um "jogo de xadrez" (GÓES, 2017a) disputado em duas Assembleias Gerais Extraordinárias, e vencido por Isabella Saboya e Sandra Guerra, candidatas apoiadas pelo grupo internacional de gestão de investimentos Aberdeen Asset Management Plc.

Finalmente, a companhia incorporou a Valepar em agosto de 2017, sustentando uma relação de substituição das ações Valepar/Vale favorável aos acionistas da primeira (grupo controlador), e caminhando no sentido da transformação da Vale em uma "sociedade sem controle definido" (VALEPAR, 2017, p. 31).

Dessa forma, a Vale obteve o ingresso no Novo Mercado da B3 em dezembro de 2017, tendo enunciado esse conjunto de mudanças organizacionais em termos morais, isto é, como um (re)ajuste orientado pelas "melhores práticas de governança corporativa" (VALE, 2017C, p. 37) e voltado a ampliar a estabilidade e a segurança para os acionistas da companhia, a liquidez da empresa (já que implicava a diversificação de sua base acionária) e, consequentemente, o acesso a recursos provenientes de mercados de capitais.

Nesses termos, a autorrepresentação desse processo como uma transformação da empresa em uma "true corporation" (SANTOS, 2017; VALE, $2017 \mathrm{~g}$ ) implicou, desde o início, em procedimentos correlatos de tipificação e confrontação de formas organizacionais. Dessa maneira, observou-se a construção de dois modelos contrastantes: um primeiro, negativo, que concebe a firma como enraizada politicamente e a caracteriza por significativa e "indevida" interferência governamental, através da participação dos fundos de pensão e do BNDES em sua estrutura acionária; e um segundo modelo, essencialmente positivo, centrado em um visão de firma desenraizada, isto é, um agente "puramente" econômico, capaz de exprimir em sua estrutura interna as características de um "mercado perfeito", conforme enunciado pela teoria econômica neoclássica (GARCIA-PARPET, 2003). A adoção desse último modelo teria sido capaz de promover uma pretensa "depuração" da influência política no controle e governança da Vale. Desse modo, a emergência de uma "nova governança corporativa" na Vale a converteria em um agente econômico e privado "puro" ou ideal (SANTOS, 2017, p. 2). 
Não obstante a adesão dos controladores da Vale e de um conjunto de agentes diversificados - associações de representação de acionistas, entidades promotoras da governança corporativa, mídia especializada, etc. - ao modelo positivo da firma, o argumento de Santos (2017) suporta a ideia de que a construção do modelo de firma pura e sua identificação ao novo regime de governança da corporação foi, em grande medida, politica. Nesses termos, o trabalho destaca a inevitabilidade do enraizamento sociopolitico da Vale, pois o processo de sua autonomização em relação a vida social (POLANYI, 2000) não se realiza completamente, já que se debruça nos próprios dispositivos de poder que denuncia, permanecendo enraizada socialmente em última instância. Assim, ainda que as CTNs estejam se organizando segundo uma lógica financeirizada, que se apresente como desenraizada da vida social, é inevitável não considerar o seu enraizamento nas relações de poder e nas normas (FLIGSTEIN E DAUTER, 2012, p. 482).

Desse modo, a reestruturação acionária da corporação aparece estreitamente associada à readequação de sua estratégia corporativa ao cenário de pós-boom das commodities ${ }^{8} \mathrm{e}$, mais profundamente, à redefinição das relações Estado-mercado no Brasil, isto é, aos limites normativos para ação legítima de agentes oriundos dessas duas esferas na atividade econômica. Em particular, essa redefinição se expressou na perda de centralidade das chamadas campeãs nacionais ${ }^{9}$ na politica econômica e no estreitamento do acesso ao crédito público, a partir da reconfiguração do papel do BNDES e através da alteração no cálculo da taxa de juros de longo prazo do banco ${ }^{10}$. A Vale, no entanto, continua a figurar no quarto lugar na lista dos maiores tomadores de recursos do banco (BNDES, 2018b).

\footnotetext{
8 As definições de boom e pós-boom das commodities minerais referem-se a condições dos mercados globais de minérios. O boom designa o período de elevação expressiva dos preços no período de 2003 a 2011. Já o pós-boom é caracterizado como um cenário de excesso de oferta, retração da demanda e perspectiva de preços baixos no longo prazo, capaz de induzir uma mudança na estratégia das empresas mineradoras, que passam a cortar custos produtivos, ao mesmo tempo em que aumentam a extração como forma de compensar as perdas do cenário negativo (Santos, 2016).

9 A partir de 2003, o BNDES adotou uma política de desembolsos centrada no apoio à internacionalização de grandes empresas de capital nacional, no que ficou conhecido como "política das campeãs nacionais". Para cumprir esse objetivo, o banco ofertou uma nova linha de crédito especial que visava estimular a inserção externa dessas empresas (Garcia, 2012).

10 Em 2018, a Taxa de Juros de Longo Prazo (TJLP) foi pela Taxa de Longo Prazo (TLP) como indexador dos financiamentos concedidos pelo BNDES. A nova metodologia de cálculo se aproxima das taxas de juros praticadas no mercado e seguindo suas flutuações, o que alterou significativamente a precificação dos créditos praticada historicamente pelo banco.
} 
Dessa maneira, Santos (2017) defende que houve uma escalada de pressões sobre a corporação no que se refere à elevação dos niveis de retorno aos acionistas e à redução de seu endividamento e custos operacionais.

Nesses termos, a "nova governança corporativa" da Vale foi:

[...] reordenada de modo essencialmente político - não se restringindo a uma dimensão econômica idealmente pura - não se voltando apenas à supressão da capacidade de influência dos agentes políticos sobre o comportamento corporativo - sejam eles internos (acionistas vinculados a fundos de pensão e bancos de participação) ou externos (Estado-nação) - mas possibilitando formas de disciplinamento financeiro modeladoras do comportamento de proprietários e dirigentes - progressivamente menos autônomos - nos âmbitos da corporação e do mercado (SANTOS, 2017, p. 3).

Dessa maneira, a ação estratégia da corporação com vistas à ampliação e estabilidade do acesso a recursos econômicos externos, que constitui um dos pilares de sua estratégia financeira, se defronta com um conjunto relativamente restrito e, mais importante, restritivo de agentes e fontes de financiamento - que se estreitaram no esteio do pós-boom das commodities, tanto da perspectiva dos investidores privados, quanto da oferta de financiamento público.

\section{Uma Nova Hierarquia de Financiamento e a Centralidade dos Investidores Institucionais}

Reafirmando a rede de financiamento da Vale como unidade de análise, o estudo empreendido constatou uma nova hierarquização dos agentes financiadores da corporação.

Assim, até recentemente, o BNDES representava o principal agente de financiamento das operações da Vale, tendo contratado $\mathrm{R} \$ 20,9$ bilhões em projetos entre 2006 e 2014 (BNDES, 2018a). Em grande medida, as relações BNDES-Vale tinham como contrapartida por parte da corporação uma combinação entre, de um lado, a ampliação e diversificação do investimento em particular, em logística e operações extrativas - e, de outro, o endividamento, articulando suas dimensões financeira e de mercado (SANTOS; MILANEZ, 2017), respectivamente.

Não obstante, o BNDES tem perdido centralidade rapidamente na busca da empresa por recursos externos. Essa redefinição é compatível com a redução progressiva do controle dos fundos de pensão e do próprio banco 
de desenvolvimento nas operações da Vale, que caracteriza o processo de implementação da "nova governança corporativa" da firma (SANTOS, 2017) e, consequentemente, a pulverização do controle que vem se dando desde então (POST ANALYST, 2017; 2018).

Desse modo, o realinhamento da estratégia corporativa da Vale às mudanças estrutural e conjuntural nos mercados de commodities e nas relações Estado-mercado no Brasil provocou uma redefinição de sua estratégia financeira, enfocando prioritariamente a redução do endividamento, a ampliação da distribuição de dividendos e a substituição parcial dos agentes e fontes de financiamento.

Nesses termos, mudanças importantes na Diretoria Executiva da corporação enfocariam prioritariamente a redução do endividamento, de US\$ 25 bilhões em 2016, para atingir uma "meta de divida liquida de US\$ 10 bilhões" (VALE, 2017e) em 2018. A ascensão do novo Chief Executive Officer da Vale, Fabio Schvartsman, em 2017 já trazia a marca da nova disciplina: "Uma empresa como essa não pode ter divida" (GÓES, 2017B).

A referida mudança assume expressão fundamental na transição do modelo de financiamento do investimento, que se desloca do endividamento ao mercado de capitais. Esse processo aparentemente endógeno acompanha, no entanto, "uma mudança marcante na linguagem da indústria", que retoma seu léxico habitual, dependente de "reduções de custo, eficiência do capital, produtividade, análise de big data, desinvestimento de ativos non-core e, sobretudo, valor ao acionista" (HUMPHREYS, 2015, p. 137).

Por sua vez, a Vale alterou sua orientação financeira com vistas a "pagar dividendos como a companhia nunca pagou na história", como justificou Schvartsman, reafirmando que seu "objetivo não é ficar com caixa e nossos investimentos são para serem feitos com as nossas ações" (GÓES, 2017b). Assim, buscando reverter uma tendência de queda do pagamento de dividendos e juros sobre o capital próprio - em 2011, a companhia distribuiu US\$ 9,0 bilhões, mas em 2016 apenas US\$250,0 milhões -, a partir de 2017 a Vale optou por ampliar a distribuição, atingindo quase US\$ 1,5 bilhão (VALE, 2018, p. 11).

Dessa forma, ao se defrontar com uma "comunidade de investidores aplicada" (HUMPHREYS, 2015, p. 137), desenvolvida durante o boom e que 
perdera seu "apetite" por investimentos na indústria extrativa mineral com a destruição de valor provocada no pós-boom (NIEPONICE et al., 2015, p. 4), agora as corporações necessitavam "reconquistar o apoio de seus acionistas desiludidos" (HUMPHREYS, 2015, p. 137).

Mais importante, a substituição dos agentes e fontes de financiamento indica um processo de "externalização" da estratégia financeira, a partir do qual a corporação pretende se abrir ao mercado de capitais.

A dimensão explícita desse processo é representada pela listagem da empresa no segmento Novo Mercado da B3. O processo sociopolítico da listagem (SANTOS, 2017) constitui, portanto, um elemento central da reconfiguração de relações entre Vale e agentes econômicos oriundos do mundo das finanças. Tais relações assumem um formato típico ator-rede, tendo em conta que o Novo Mercado pode ser compreendido como um dispositivo capaz de integrar elementos heterogêneos - humanos e não humanos - em relações de poder e saber; assim como a Vale pode ser vista como um nó-chave no qual se encontram diferentes redes globais de produção, dinamizando processos de acumulação em âmbito produtivo e financeiro.

Entretanto, a capitalização de mercado no Brasil - que caiu de US\$ 1,54 bilhões para US\$ 954,7 milhões, ou de 70\% para 41,1\% do Produto Interno Bruto (PIB) do país, entre 2010 e 2017 (WORLD BANK, 2018) - não parece proporcionar uma fonte barata, constante e suficientemente volumosa de crédito. Em paralelo, as operações internacionalizadas da Vale demandam fontes de recursos externos menos concentradas que as ofertadas pelo mercado de capitais brasileiro.

Dessa forma, instado a se posicionar sobre o potencial de diversificação do financiamento da corporação, Schvartsman afirmava em fins de 2017 que:

[...] essa é uma nova possibilidade para a Vale, agora que estamos mudando para o Novo Mercado no Brasil e estamos melhorando os padrões de governança, o que nos dará a alternativa de listagem na Bolsa de Valores de Londres. Isso não era possivel de antemão. Agora é possível [...] (SCHVARTSMAN ET AL., 2017, p. 12).

Não obstante, há ainda uma dimensão implícita, particularmente relevante, desse processo, impondo consideração mais detalhada do papel dos fundos de investimento externos. 
Em primeiro lugar, durante a mobilização pela listagem no Novo Mercado da B3, observou-se uma retomada do "apetite" (NIEPONICE et al., 2015, p. 4) dos chamados investidores institucionais por ações da mineradora, que elevaram substancialmente suas posições na companhia entre outubro de 2017 e abril de 2018: de US\$ 5,12 bilhões (10,5\% do valor de mercado) para US\$ 13,98 bilhões (19,9\% da capitalização) (POST ANALYST, 2017; 2018).

Os três maiores investidores institucionais da empresa estão apresentados na tabela abaixo (Tabela 1):

Tabela 1 - Maiores investidores institucionais

\begin{tabular}{lrr}
\hline \multicolumn{1}{c}{ Principais Investidores Institucionais } & Valor das ações detidas & \multicolumn{2}{c}{ Valor de mercado } \\
\hline Capital Research Global Investors & US\$ 1,93 bilhão & $2,91 \%$ \\
\hline Blackrock Inc. & US\$ 1,35 bilhão & $2,04 \%$ \\
\hline Aberdeen Asset Management PIC & US\$ 1,22 bilhão & $1,85 \%$ \\
\hline TOTAL & US\$ 13,98 bilhões & $19,9 \%$ \\
\hline
\end{tabular}

Fonte: os autores, a partir de Post Analyst (2018).

A retomada do "apetite" (NIEPONICE et al., 2015, p. 4) seria acompanhada, não obstante, pela exigência de mais disciplina por parte das corporações financiadas. Assim, o segundo maior fundo de investimentos estrangeiro na Vale, já em 2013, no esteio de uma depreciação do valor dos ativos que custou o posto de Tom Albanese, Cost Chief Executive da Rio Tinto, se manifestava explicitamente acerca da mudança na natureza da relação financiador-financiado no setor extrativo. Evy Hambro, Diretor de Portfólio da BlackRock, se dirigia a corporações "tão imprudentes e perdulárias com o capital dos acionistas do qual deveriam ser custodiantes" (THE AUSTRALIAN, 2013). Para ele seria necessária "maior disciplina de capital no interior dessas empresas, [...] companhias muito mais diligentes em suas análises, [...] [e] diretorias responsáveis, bem como os executivos, por esses negócios" (THE AUSTRALIAN, 2013). Em certo sentido, era fundamental que a liberdade das Diretorias Executivas e Conselhos de Administração das mineradoras fosse tolhida, uma vez que esses agentes tinham se servido "abusivamente" dela.

É nesses termos que a Aberdeen Asset Management Plc. assume papel relevante na reconfiguração da Vale como uma true corporation (VALE, 2017g). Desse modo, a "nova governança corporativa" da Vale se desfaz 
progressivamente de um modo de financiamento visto como quasiempresarial, em favor de uma estrutura de propriedade cada vez mais próxima àquelas das principais corporações do setor de minério de ferro.

Dois movimentos ajudam a explicar essa posição-chave recém assumida. Em primeiro lugar, a Aberdeen se distanciou de outros investidores institucionais da Vale - em especial, os fundos Tempo Capital, e Geração Futuro L. Par., detentores importantes de ações preferenciais - na Assembleia Geral Extraordinária de abril de 2017. Assim, a gestora de investimentos rejeitou o uso do voto múltiplo e, consequentemente, solapou a possibilidade de eleição de dois membros independentes para o Conselho de Administração. Esse primeiro movimento se alinhava à orientação da Vale de eleger apenas um membro independente naquele momento.

O movimento complementar, realizado pela Vale, se baseou na alegação de descumprimento de exigências da Lei das SAs, de modo que muitos representantes dos acionistas foram interditados, o que impediu a obtenção de quórum e, consequentemente, a própria eleição.

Por sua vez, no pleito de outubro de 2017, quando a eleição de dois representantes independentes havia se tornado mandatória, a Aberdeen lançou duas candidatas ao Conselho de Administração, que representavam acionistas majoritários e minoritários, no que foi bem-sucedida.

O resultado geral desse processo tem sido uma expansão considerável do controle acionário da corporação por parte de investidores institucionais estrangeiros, mas que não prescinde de influência desproporcional de uma organização específica, a Aberdeen. Em parte, sua habilidade em conjugar sua posição acionária recém ampliada com uma influência desproporcional no Conselho de Administração, ainda que mediada por representação "independente", deve-se ao papel exercido pela Aberdeen do Brasil Gestão de Recursos Ltda., sua subsidiária instalada no país. Essa influência contrasta, entretanto, mesmo que parcialmente, com a perspectiva de uma corporação plena, de controle pulverizado, mas que se aproxima progressivamente do perfil setorial da mineração. 


\section{Considerações finais}

Em linhas gerais, a transformação da governança corporativa da Vale corresponde a uma alteração nas relações ator-rede, redefinindo as condições de integração entre corporação e agentes financeiros. Não obstante, o conjunto das mudanças na RGP da Vale se estende também aos agentes não econômicos e suas relações, de maneira que a trajetória da mudança organizacional é pavimentada por enfrentamentos materiais e simbólicos que acabaram por conduzir a firma desenraizada à condição de modelo normativo suficientemente flexivel para manter-se em vigor em rodadas potenciais de desenraizamento sociopolítico.

Tais transformações são, entretanto, articuladas e, parcialmente, condicionadas por mudanças mais amplas: (i) nas condições relativamente restritivas de acumulação de capital na indústria extrativa mineral a partir do pós-boom das commodities, definidoras dos nós financeiros das redes globais de produção de CTNs mineradoras, e de suas oportunidades para acessar recursos externos; e (ii) no reajuste neoliberal das relações Estado-mercado no Brasil - relacionadas ao item i -, que adicionou uma condição restritiva à obtenção de crédito por parte da Vale, com o progressivo eclipse do BNDES como agente-chave de financiamento.

Desse modo, o processo de espelhamento da composição acionária da Vale a um perfil setorial, com estrutura unificada de ações e controle disperso apresenta uma dimensão exógena relevante, que corresponde a dinâmicas de financeirização explícitas.

No entanto, os engajamentos e desengajamentos múltiplos de agentes diversificados têm sido claramente relevantes para evidenciar:

(i) o exercício do poder corporativo (SANTOS; MILANEZ, 2018) como supressão da resistência interna à mudança da governança da firma, com ênfase na capacidade da Diretoria Executiva e do Conselho de Administração da Vale e de agentes externos - como a Aberdeen, associações em defesa dos interesses de acionistas minoritários, etc. - em canalizar as demandas de acionistas e influenciar a opinião pública em favor do tipo da firma desenraizada; 
(ii) a centralidade dos processos de construção institucional associados ao tipo em questão e, em particular, ao dispositivo do Novo Mercado da B3, que, reconfigurado a partir do ingresso da Vale, assume potencial de modelagem do mercado de capitais brasileiro;

(iii) a relevância crescente de investidores institucionais estrangeiros e de mercados dos capitais externos, em detrimento do financiamento público doméstico e de seus agentes-chave - o BNDES, em particular -, que, a despeito da promessa de ampliação do acesso a recursos externos, tende a promover ativamente formas de disciplinamento financeiro da corporação, reduzindo a autonomia de seus quadros dirigentes. Tais agentes vêm sendo incorporados concreta e/ou potencialmente às narrativas dos relatórios como financiadores (e controladores difusos) sob a mediação da avaliação de intérpretes autorizados, como as agências de classificação de risco.

Sendo assim, duas dimensões da análise merecem ser acentuadas. Se, de um lado, o processo de financeirização, entendido como reestruturação das oportunidades e restrições à acumulação de capital e ao exercício do poder corporativo, é indutor de mudanças organizacionais endógenas em CTNs extrativas; de outro, são os agentes e suas relações em rede que modulam esse processo.

No caso dos agentes internos à corporação, a orientação de retração da estratégia corporativa ao seu core business e à redução da dívida ressurgem como práticas gestionárias eficientes, favorecendo uma interpretação curtoprazista da estratégia financeira (JACKSON; PETRAKI, 2011) da Vale.

A divida assume um papel disciplinador relevante nesse contexto, operando com um índice de eficiência dos quadros diretivos. Entretanto, seu reposicionamento no centro do léxico corporativo da eficiência assume características de construção social partilhada por múltiplos agentes, em particular, exógenos à corporação, sendo central, por exemplo, nas avaliações das agências de classificação de risco, gatekeepers de decisões pulverizadas de investimento. A busca sistemática de sua redução como prioridade-chave da estratégia financeira da Vale deve, dessa forma, ser entendida duplamente 
a partir de pressões exógenas difusas e da ação estratégica de seus quadros dirigentes.

Dessa maneira, a transformação organizacional pela qual a Vale vem passando é convergente como um duplo movimento. Primeiramente, implica a existência de padrões estruturais de disciplinamento financeiro da firma, predominantemente exógenos e capazes de instituir uma nova institucionalidade no mercado de capitais brasileiro, em particular no que respeita às regras relativas à estrutura de governança e aos direitos dos acionistas. Particularmente importantes nesse sentido parecem ser os membros do Conselho de Administração e seu segmento independente, como vetores institucionais desse padrão disciplinar. Por sua vez, a referida transformação demanda mecanismos de disciplinamento organizacional, essencialmente endógenos e, parcialmente pedagógicos, orientandos à reconfiguração do comportamento do investidor individual. Nesse âmbito, as relações públicas entre quadros dirigentes e investidores assume papel importante, demandando táticas específicas no âmbito da estratégia social da corporação.

Finalmente, as transformações da carteira de financiadores da Vale demandam análise diacrônica, de maneira que os resultados parciais da investigação aqui apresentados não foram ainda capazes de proporcionar. Não obstante, a focalização de um momento de redefinição das relações financiadores-financiado permitiu ilustrar uma representação diversa e hierarquizada da rede de relações de financiamento na qual se insere uma CTN do setor extrativo, abrindo espaço para abordagens complementares e mais aprofundadas.

\section{Referências}

AGUILERA, R. V.; JACKSON, G. The cross-national diversity of corporate governance: dimensions and determinants. Academy of Management Review, v. 28, n. 3, p. 447-465, 2003.

AQUINO, C. A. B. Contribuição das análises sociológicas do discurso às pesquisas no campo do trabalho. In: ALVES, G. S., J. B. F. Métodos e técnicas de pesquisa sobre o mundo do trabalho. Fortaleza: Projeto Editorial Práxis, 2014. p.193-203.

BM\&FBOVESPA. Segmentos de listagem: Novo Mercado [Online]. BM\&FBOVESPA. Disponivel em: < 
http://www.bmfbovespa.com.br/pt_br/listagem/acoes/segmentos-delistagem/novo-mercado/ >. Acesso em: 15 apr.

BNDES. Operações diretas e indiretas não automáticas contratadas pela Vale S.A. junto ao BNDES. Rio de Janeiro: BNDES, 2018a.

Quem são os nossos 50 maiores tomadores de recursos. Rio de Janeiro: BNDES, 2018b.

CALLON, M. Introduction: the embeddedness of economic markets in economics. The Sociological Review, v. 46, n. S1, p. 1-57, 1998.

CALLON, M.; MUNIESA, F. Peripheral vision: economic markets as calculative collective devices. Organization Studies, v. 26, n. 8, p. 1229-1250, 2005.

DAVIS, G. F. Politics and financial markets. In: KNORR CETINA, K.; PREDA, A. The Oxford Handbook of the Sociology of Finance. Oxford: OUP, 2012. p.72-95.

DAVIS, G. F.; KIM, S. Financialization of the Economy. Annual Review of Sociology, v. 41, p. 203-221, 2015.

FLIGSTEIN, N. Markets as politics: a political-cultural approach to market institutions. American Sociological Review, p. 656-673, 1996.

FLIGSTEIN, N.; DAUTER, L. A sociologia dos mercados. Caderno CRH, v. 25, p. 481-504, 2012.

FROUD, J.; HASLAM, C.; JOHAL, S. et al. Shareholder value and financialization: consultancy promises, management moves. Economy and Society, v. 29, n. 1, p. 80-110, 2000.

GARCIA-PARPET, M. F. A construção social de um mercado perfeito: o caso de Fontaines-en-Sologne. Estudos Sociedade e Agricultura, v. 20, p. 5-44, 2003.

GARCIA, A. E. S. A internacionalização de empresas brasileiras durante o governo Lula: uma análise critica da relação entre capital e Estado no Brasil contemporâneo. [Tese (doutorado)]. Programa de Pós-graduação em Relações Internacionais, Pontificia Universidade Católica do Rio de Janeiro, Rio de Janeiro, 2012.

GÓES, F. Investidor pede e Vale muda boletim de voto na AGE. Valor Econômico, Rio de Janeiro, 4 out. 2017a. Disponivel em: < http://www.valor.com.br/empresas/5143924/investidor-pede-e-vale-mudaboletim-de-voto-na-age >. Acesso em: 10 abr. 2018.

Vale reduz meta de endividamento para US\$ 10 bilhões. Valor Econômico, Rio de Janeiro, 5 dez. 2017b. Disponivel em: < http:/ / www.valor.com.br/empresas/5217565/vale-reduz-meta-deendividamento-para-us-10-bilhoes >. Acesso em: 10 abr. 2018. 
GRÜN, R. Decifra-Me ou te Devoro: o Brasil e a Dominação Financeira. São Paulo: Alameda, 2015.

HAENSEL, T. A figura dos gatekeepers: aplicação às instituições intermediárias do mercado organizado de valores mobiliários brasileiro. [Dissertação (mestrado)]. Faculdade de Direito, Universidade de São Paulo, São Paulo, 2014.

HEILBRON, J. Taking stock: toward a historical sociology of financial regimes. Economic Sociology, v. 7, n. 1, p. 3-17, 2005.

HENDERSON, J.; DICKEN, P.; COE, N. et al. Redes de produção globais e a análise do desenvolvimento econômico. Revista Pós Ciências Sociais, v. 8, n. 15, p. $143-170,2011$.

HESS, M. 'Spatial'relationships? Towards a reconceptualization of embedded ness. Progress in Human Geography, v. 28, n. 2, p. 165-186, 2004.

HUMPHREYS, D. The Remaking of the Mining Industry. Basingstoke: Palgrave Macmillan, 2015.

JACKSON, G.; MIYAJIMA, H. Introduction: the diversity and change of corporate governance in Japan. In: AOKI, M.; JACKSON, G.; MIYAJIMA, H. Corporate Governance in Japan: institutional change and organizational diversity. Oxford: OUP, 2007. p.1-47.

JACKSON, G.; PETRAKI, A. Understanding short-termism: the role of corporate governance. Stockholm: Glasshouse Forum, 2011.

KNORR CETINA, K.; PREDA, A. (Org.). The Sociology of Financial Markets. Oxford: OUP, 2005.

(Org.). The Oxford Handbook of the Sociology of Finance. Oxford: OUP, 2012.

LEITE, E. d. S. Reconversão de habitus: o advento do ideário de investimento no Brasil. [Tese (doutorado)]. Programa de Pós-Graduação em Sociologia, Universidade de São Carlos, São Carlos, 2011.

MACKENZIE, D.; MUNIESA, F.; SIU, L. (Org.). Do economist make markets? On the performativity of economics. Princeton: Princeton University Press, 2007.

MAMONA, K. Vale lidera lista das empresas que mais ganharam valor em abril. Exame, São Paulo, 2 mai. 2018. Disponivel em: < https://exame.abril.com.br/mercados/vale-lidera-lista-das-empresas-quemais-ganharam-valor-em-abril/ >. Acesso em: 5 mai. 2018.

MILANEZ, B.; SANTOS, R. S. P. d.; MAGNO, L. et al. A Estratégia Corporativa da Vale S.A.: um modelo analitico para Redes Globais Extrativas. Versos. Textos para Discussão PoEMAS, v. 2, n. 2, p. 1-43, 2018. 
MORGAN, G.; KRISTENSEN, P. H. The contested space of multinationals: varieties of institutionalism, varieties of capitalism. Human Relations, v. 59, n. 11, p. 1467-1490, 2006.

NIEPONICE, G.; VOGT, T.; KOCH, A. et al. Value Creation in Mining 2015: beyond basic productivity. Boston: Boston Consulting Group, 2015.

PELA, J. K. Origem e desenvolvimento das golden shares. Revista da Faculdade de Direito, Universidade de São Paulo, v. 103, p. 187-238, 2008.

POLANYI, K. A grande transformação: as origens de nossa época. Rio de Janeiro: Campus, 2000.

POST ANALYST. Aberdeen Asset Management Plc/UK is the Second Biggest Holder of Vale S.A. (VALE). Post Analyst, 6 out. 2017. Disponivel em: < https:/ / postanalyst.com/2017/10/06/aberdeen-asset-management-plcukis-the-second-biggest-holder-of-vale-s-a-vale/ >. Acesso em: 10 abr. 2018.

The Biggest 3 Holders of Vale S.A. (NYSE:VALE). Post Analyst, 2 abr. 2018. Disponivel em: < https://postanalyst.com/2018/04/02/the-biggest-3holders-of-vale-s-a-nysevale/ > . Acesso em: 10 abr. 2018.

PREDA, A. Sense and sensibility: or, how should Social Studies of Finance behave? A Manifesto. Economic Sociology: European Electronic Newsletter, v. 2, n. 2, p. 15-18, 2001.

RÓSTAS, R. Desafio de mineradoras é criar valor para acionistas. Valor Econômico, 27 aug. 2015. Disponivel em: < http://www2.valor.com.br/empresas /4197794/desafio-de-mineradoras-ecriar-valor-para-acionistas >. Acesso em: 30 out. 2016.

SANTOS, R. S. P. Redes de Produção Globais (RPGs): contribuições conceituais para a pesquisa em ciências sociais. Revista Pós Ciências Sociais, v. 8, n. 15, p. 127-142, 2011.

Análise de Conjuntura: boom e pós-boom da mineração. In: Seminário 'Modelo de Extrativismo Mineral Sob Critica', Vitória, 2016.

A nova governança corporativa da Vale S.A.: um percurso político em direção à "true corporation". Versos. Textos para Discussão PoEMAS, v. 1, n. 5 , p. 1-17, 2017.

SANTOS, R. S. P.; MILANEZ, B. Apresentação. Estratégias corporativas no setor extrativo: uma agenda de pesquisa para as ciências sociais. Caderno Eletrônico de Ciências Sociais, v. 5, n. 1, p. 1-26, 2017.

Poder Corporativo e Ação Econômica: reflexões a partir da mineração de ferro. Politica \& Trabalho, n. 48, p. 95-113, 2018.

SARTORE, M. d. S. Convergência de elites: a sustentabilidade no mercado financeiro. [Tese (doutorado)]. Programa de Pós-Graduação em Ciências Sociais, Universidade Federal de São Carlos, São Carlos, 2010. 
SASSEN, S. The embeddedness of electronic markets: the case of global capital markets. In: KNORR CETINA, K.; PREDA, A. The Sociology of Financial Markets. Oxford: OUP, 2006. p.17-37.

SCHVARTSMAN, F.; POPPINGA, P.; MAKI, J. et al. Vale Day 2017 Press Conference. London: Vale, 2017.

THE AUSTRALIAN. Miners have lost investors' trust, says BlackRock's Evy Hambro. The Australian Business Review, Sidney, 18 jan. 2013. Disponivel em: < https://www.theaustralian.com.au/business/mining-energy/bn-hitforces-rio-to-change-guard/news-

story / f81c75780170a1306ede3668b8791f73?sv=350a4eb97dd29db5397240 f38e561875 >. Acesso em: 10 abr. 2018.

VALE. Composição Acionária [Online]. Vale. Disponível em: < http://www.vale.com/brasil/PT/investors/company/shareholdingstructure/Paginas/default.aspx >. Acesso em: 10 abr. 2018.

Formulário 20-F. Relatório Anual 2016. Vale, 2017a.

Formulário de Referência 2017. Vale, 2017b.

Manual para Participação na Assembleia Geral Extraordinária da Vale S.A. (21 de dezembro de 2017). Rio de Janeiro: 2017c.

Proposta para Destinação do Resultado do Exercicio Social encerrado em 31 de dezembro de 2016. Rio de Janeiro: Vale, 2017d.

Relatório da Administração. Desempenho da Vale em 2017. Rio de Janeiro: Vale, 2017e.

- A Vale em números [Online]. Vale. Disponivel em: < http://www.vale.com/brasil/pt/aboutvale/across-

world/paginas/default.aspx >. Acesso em: 10 abr. 2018.

Vale: a caminho da true corporation. Vale, $2017 \mathrm{~g}$.

Formulário 20-F. Relatório Anual 2017. Vale, 2018.

VALEPAR. Acordo de Acionistas Valepar S.A. Rio de Janeiro: 2017.

VAN DER ZWAN, N. Making sense of financialization. Socio-economic Review, v. 12, n. 1, p. 99-129, 2014.

WEBER, M. Economia e Sociedade: fundamentos da sociologia compreensiva. Brasília: EdUnB, 1999.

WILLIAMS, K. From shareholder value to present-day capitalism. Economy and Society, v. 29, n. 1, p. 1-12, 2000.

WORLD BANK. World Development Indicators: stock markets. World Bank, 2018. 